\title{
Evidence for an immune complex vasculitis in neonatal necrotising enterocolitis
}

\author{
ELIZABETH S GRAY, DAVID J LLOYD, STANLEY S MILLER, \\ ALAN I DAVIDSON, NICOLA J BALCH, CHARLES HW HORNE
}

From the Department of Pathology, University of Aberdeen, the Department of Neonatal Paediatrics, Aberdeen Maternity Hospital and University of Aberdeen, and Surgical Unit, Royal Aberdeen Children's Hospital

SUMMARY Despite many attractive hypotheses, neonatal necrotising enterocolitis (NNEC) remains a disease of unknown aetiology. By means of the immunofluorescent direct sandwich technique we have demonstrated immune complex deposition in the small vessels of the diseased bowel wall. We believe this is the first report of evidence of an immunological reaction occurring in this disease.

In 1979 Tait and Kealy ${ }^{1}$ described in detail the histopathological features of neonatal necrotising enterocolitis (NNEC), a potentially fatal condition predominantly affecting low birth weight preterm infants in modern intensive care nurseries. The disease consists of a fulminating necrosis of the intestinal tract together with production of gas within the bowel wall (pneumatosis intestinalis), the latter presumably being due to invasion of the tissues by gas producing bacteria.

Although a variety of hypotheses has been proposed, the aetiology, despite much research, is still unknown. Interest has centred recently on the bacterial flora of the affected bowel, especially on the role of the clostridia. ${ }^{2}$ However, in 1977, Lake and Walker ${ }^{3}$ studying immune defence mechanisms in neonatal gut, in particular the role of secretory IgA in the regulation of antigen absorption, suggested that as the neonatal gut had such a precarious defence against excessive absorption of antigen, NNEC

Accepted for publication 19 November 1980 could be due to an altered host defence. Unfortunately they could offer no clinical or laboratory evidence to support this hypothesis.

We report here four patients with NNEC, in three of whom we found evidence of an immune reaction. To the best of our knowledge we believe these to be the first patients with NNEC in which immunological features have been demonstrated.

\section{Patients and methods}

The four infants were patients requiring treatment in the Special Care Nursery in the Aberdeen Maternity Hospital. Brief clinical details are supplied in Table 1.

Before fixation in $10 \%$ neutral buffered formalin, fresh tissue was obtained from the acutely diseased bowel of three infants with NNEC requiring emergency surgical intervention. In one (case 1) further material was obtained at necropsy and in another (case 3) only necropsy biopsies were available. In all four patients portions of necrotic and of less

Table 1 Immunoglobulins, complement $(C 3)$ and fibrin deposition within the small vessels of diseased bowels in NNEC using the immunofluorescent technique

\begin{tabular}{|c|c|c|c|c|c|c|c|c|}
\hline \multirow[t]{2}{*}{ Case No } & \multicolumn{2}{|l|}{ Clinical summary } & \multirow[t]{2}{*}{ Outcome } & \multirow[t]{2}{*}{$I g G$} & \multirow[t]{2}{*}{$\operatorname{Ig} A$} & \multirow[t]{2}{*}{$\operatorname{Ig} M$} & \multirow[t]{2}{*}{$C 3$} & \multirow[t]{2}{*}{ Fibrin } \\
\hline & Gestational age (wk) & Age at biopsy (days) & & & & & & \\
\hline 1 & 32 & 6 & $\begin{array}{l}\text { died } \\
\text { (9 days) }\end{array}$ & 0 & 0 & 0 & ++ & $+t$ \\
\hline 2 & 37 & 8 & alive & 0 & 0 & + & + & + \\
\hline 3 & 29 & 12 & $\begin{array}{l}\text { died } \\
\text { (12 days) }\end{array}$ & 0 & + & ++ & ++ & ++ \\
\hline 4 & 30 & 12 & alive & 0 & + & ++ & ++ & ++ \\
\hline
\end{tabular}

0 to $+++=$ arbitrary scale of fluorescence intensity. 
obviously involved intestine were snap-frozen and the presence of $\operatorname{IgG}, \operatorname{IgA}, \operatorname{IgM}, \mathrm{C} 3$, and fibrin detected in the cryostat-cut sections by the direct immunofluorescent technique with commercially prepared fluorescein-labelled antibody (Burroughs Wellcome Ltd and Hoechst Pharmaceuticals). After fixation, tissue was processed and $5 \mu \mathrm{m}$ sections cut and stained by the haematoxylin and eosin (H \& E) method.

\section{Results}

Our immunopathological findings are shown in Table 1. The intensity of the fluorescence is scored on an arbitrary scale 0 to +++ .

In three of the infants (cases 2, 3, 4) there was deposition of IgM (Fig. 1) C3, and fibrin within the lumina and walls of the small vessels of the diseased bowel both in the totally necrotic areas and in sections less severely involved (even macroscopically

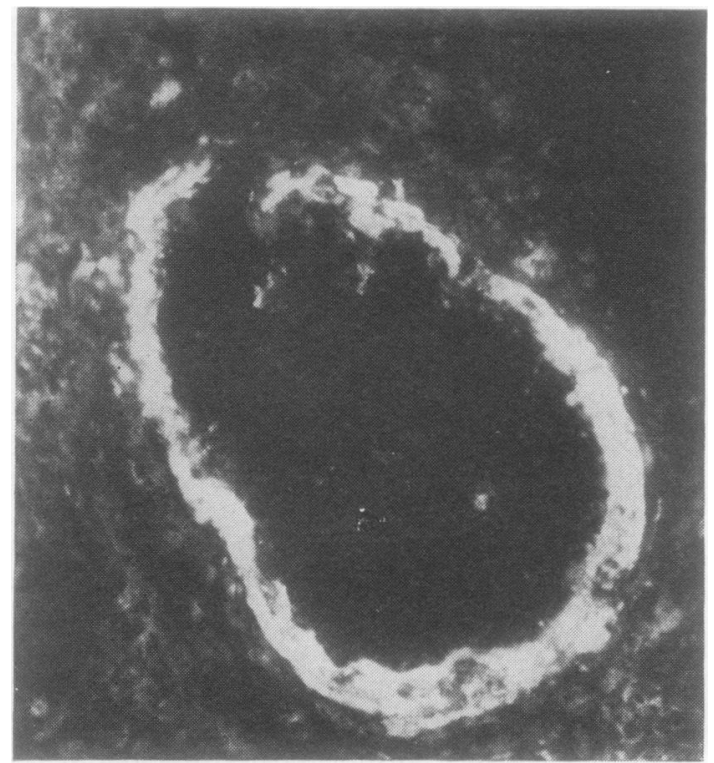

Fig. 1 IgM deposition within the vessel walls demonstrated by fluorescein-labelled anti-IgM normal bowel showed ulceration on histologica? examination). IgA was present also in two patiento (cases 3,4), while IgG was detected in none of the infants.

A more detailed immunopathological examination was possible from necropsy specimens in two patient (cases 1,3 ) and in addition to diseased bowel $\frac{\bar{p}}{?}$ tissue was obtained from histologically normaß bowel, the larger mesenteric vessels, and frons kidney. The findings are shown in Table 2 with neither case demonstrating immunoglobulin nor complement deposition in the glomeruli. In case $\vec{z}$ the immunoglobulins and complement were detect? able only in the vessels of diseased bowel but nof in normal bowel nor in larger mesenteric vessels In case 1 no immunoglobulins were found in an义 tissue although complement and fibrin were preseni in the smaller vessels of all the sections of bowele and also in the larger mesenteric vessels.

Examination of the sections stained by the $\mathrm{H} \& \mathrm{E}$ method showed in all cases the typical histologicale appearances of NNEC. Although vascular changes are not considered a notable feature, we did findo evidence of vascular damage in cases 2,3 , and $4 \stackrel{\infty}{\rightleftarrows}$ Some of the small vessels in the damaged bowel walt showed perivasculitis (Fig. 2), fibrinoid necrosis (Fig. 3), and thrombosis with vessel wall damage anc haemorrhage (Fig. 1). In case 1, fibrin deposition was noted in the vessels and there was no associated inflammatory reaction.

\section{Discussion}

The association of immunoglobulin, complement and fibrin (cases 2, 3, 4, Table 1) within the lumero and walls of blood vessels is generally accepted as indicating intravascular immune complex deposition (ICD). The presence of complement and fibrin im only case 1 may indicate that complement was being activated within the vessel by a non-immuno은 logical process - that is, via the alternative pathway

In each of the three neonates with evidence o․ local immune complex composition the antibodyn involved was of the IgM class, the intensity of the fluorescent staining being most marked in the

Table 2 Immunoglobulin, complement (C3) and fibrin deposition within the vessels of tissue from different sites at ${ }_{<}$ time of necropsy

\begin{tabular}{|c|c|c|c|c|c|c|}
\hline \multirow[t]{2}{*}{ Site of biopsy } & \multicolumn{3}{|c|}{ Case 1} & \multicolumn{3}{|c|}{ Case 3} \\
\hline & $I g M$ & $C 3$ & Fibrin & $I g M$ & $C 3$ & Fibrir \\
\hline $\begin{array}{l}\text { Necrotic bowel } \\
\text { Normal bowel } \\
\text { Larger mesenteric vessels } \\
\text { Renal glomeruli }\end{array}$ & $\begin{array}{l}\mathbf{0} \\
\mathbf{0} \\
\mathbf{0} \\
\mathbf{0}\end{array}$ & $\begin{array}{l}++ \\
+ \\
+ \\
0\end{array}$ & $\begin{array}{l}\because+ \\
+4 \\
+ \\
0\end{array}$ & $\begin{array}{l}++ \\
0 \\
0 \\
0\end{array}$ & $\begin{array}{l}++ \\
0 \\
0 \\
0\end{array}$ & $\begin{array}{l}++ \\
+1 \\
\vdots \\
0 \\
0\end{array}$ \\
\hline
\end{tabular}




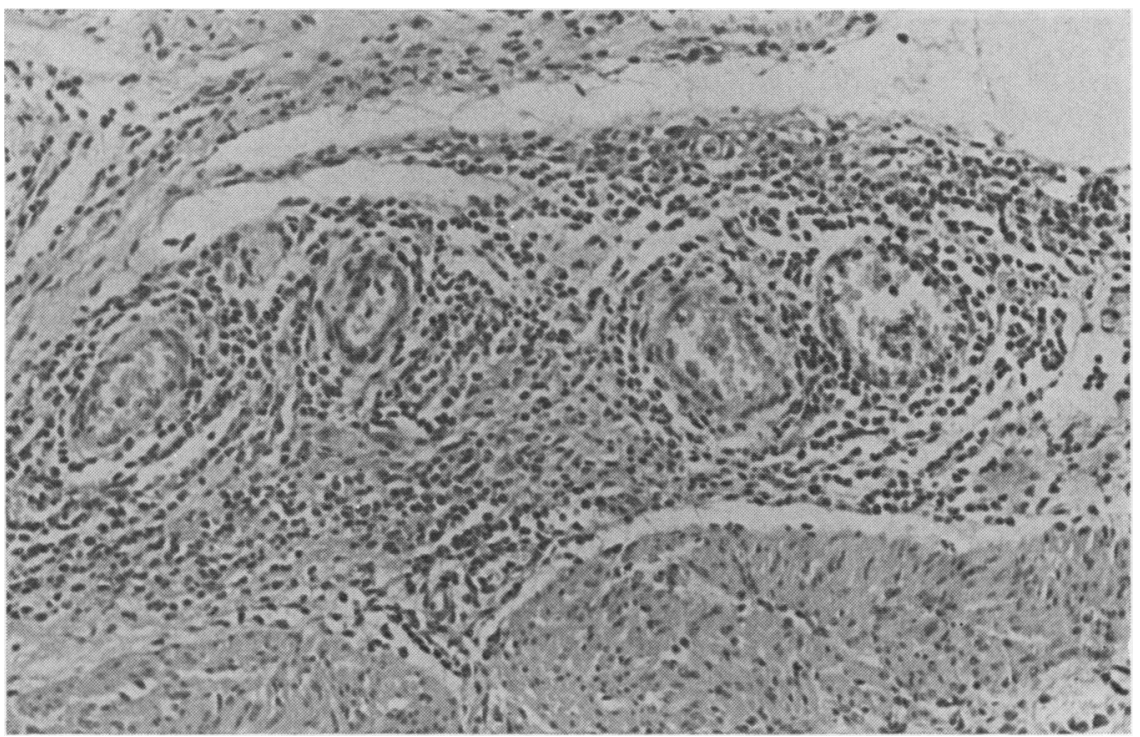

Fig. 2 Perivasculitis of small vessels in the bowel wall.

Haematoxylin and eosin $\times 256$

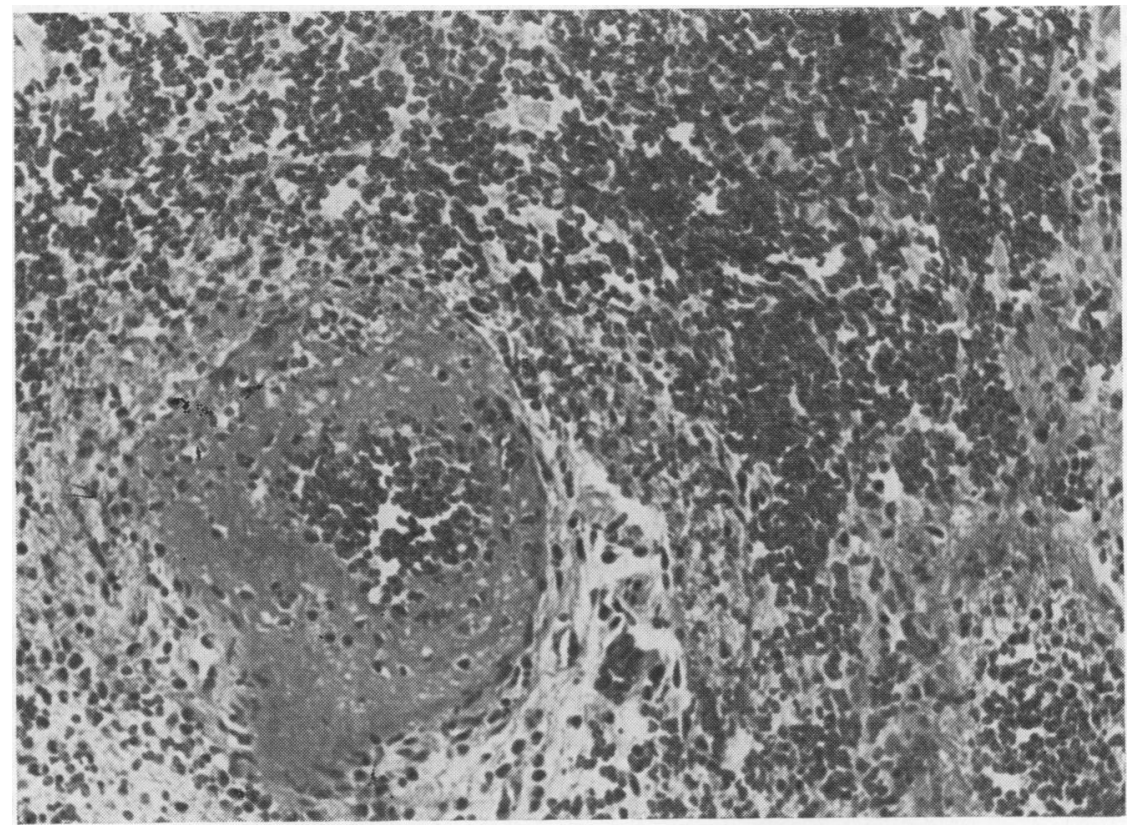

Fig. 3 Fibrinoid necrosis of bowel wall arteriole. Haematoxylin and eosin $\times 650$

"older" infants. As maternal IgM cannot cross the placental barrier this IgM must be fetal or neonatal in origin. IgG was not detected presumably because IgG antibody appears later in the immune response. The presence of IgM and the absence of IgG indicate a recent exposure to the unknown antigen. IgA was present, in addition to IgM, in two of the three patients. IgA, just detectable in cord blood, is produced in neonates after about one week in response to antigenic stimuli.

We have demonstrated ICD in the small vessels of three patients with NNEC (Table 1) and, in the only case with ICD to come to necropsy, have shown that this is a localised deposition (Table 2).

Two different immunological mechanisms could produce this particular pattern of ICD. One is the 


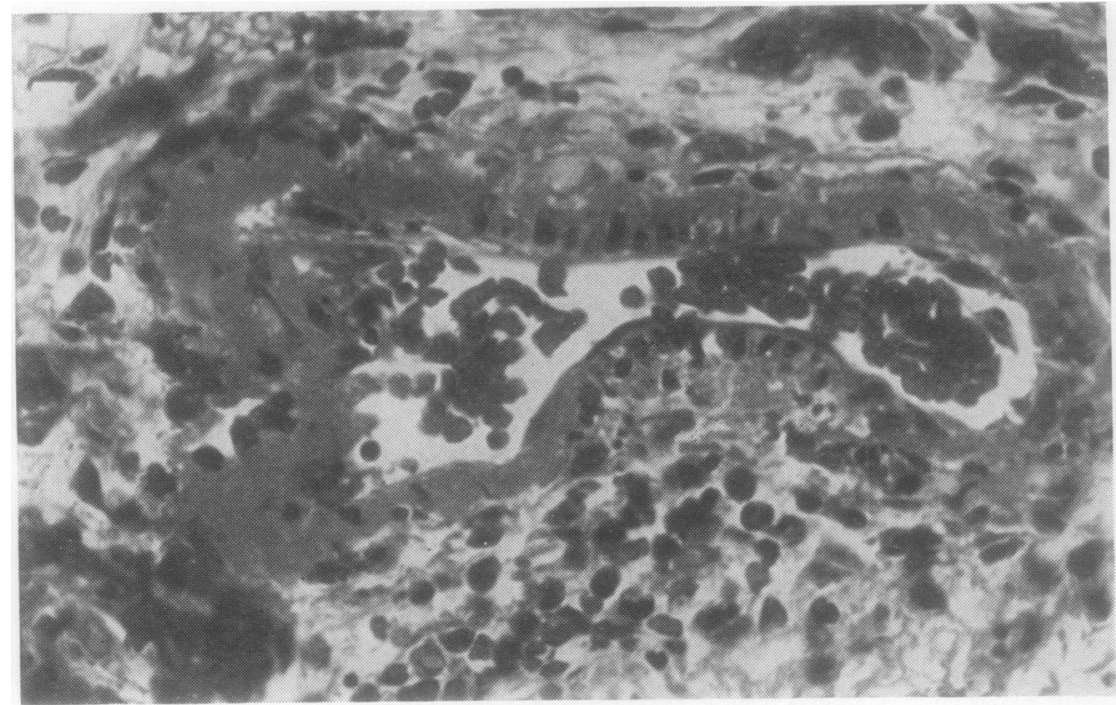

Fig. 4 Fibrin deposition and rupture के of an arteriole in bowet wall. Haematoxylin and eosin $\times 256$
Auer phenomenon in which circulating antigen antibody complexes are preferentially deposited in areas of tissue damage, and the other is the Arthus reaction. While the Auer phenomenon cannot be completely disregarded, the failure to demonstrate histological evidence of circulating complexes implies that this is an Arthus reaction. Experimentally the Arthus reaction is produced by injecting antigen, usually intradermally, into an already sensitised animal. Antigen/antibody complexes form in the vessels and their walls at the site of the injection -that is, where there is antigen excess. The histological sequelae to this are perivasculitis, oedema, acute inflammation, haemorrhage, and necrosis, such as we have observed in our cases of NNEC.

It is known from studies of antimilk antibodies in the human neonate that antigen passes more easily through the intestinal mucosa in neonates than in adults. ${ }^{4}$ There is also good experimental evidence that, when the neonatal mucosal barrier to antigen is damaged by vascular insufficiency, or ileus, massive antigen diffusion occurs. ${ }^{5}$ In human neonates it has been suggested that vascular insufficiency of the intestine may be caused by a variety of clinical situations including hypoxia, ${ }^{6}$ hyperviscosity, ${ }^{7}$ plasticisers from PVC catheters, ${ }^{8}$ and stress, ${ }^{9}$ all conditions associated with an increased incidence of NNEC.

We suggest that an Arthus type reaction develops in NNEC due to a localised breakdown in the integrity of the mucosa, allowing antigen from the bowel lumen to be absorbed in large quantities so provoking a specific immune response. If antigen continues to enter the interstitium, then with the formation of circulating antibodies, immune com- plexes will be deposited in this area of antigen excess

Having demonstrated this immunological phenoळ menon how significant is it? It could simply be an epiphenomenon, as are many of the antibodies detected in human disease. However, there is histological evidence to suggest that an Arthus typ reaction may have a role in the evolution of at least some, although probably not all, cases of NNEC $\stackrel{\mathbb{Q}}{\Omega}$

Firstly, ICD in vessels is followed by a peri $\vec{\overrightarrow{ }}$ vasculitis and, although vasculitis has not bee! considered previously to be a feature of NNEC, we have shown it to be present in a proportion of oup cases. Secondly, ICD in vessels leads to fibrin an platelet aggregates and this certainly is a striking feature in many cases of NNEC. Thirdly, in 1959? Goldgraber and Kirsner, ${ }^{10}$ whileattempting to produce an experimental animal model for ulcerative colitis anf Crohn's disease, induced an Arthus reaction in the colons of rabbits sensitised to egg albumin. He failed to produce the chronic inflammatory condition of ulcerative colitis but did produce an acute lesion characterised by oedema, haemorrhage, and tissuê necrosis of the colon. His detailed histologica, descriptions and excellent photomicrographs shore many similar features to those present in NNEC Fourthly, in 1965, Hermann, ${ }^{11}$ on the basis of histo logical observations of NNEC, suggested that the masses of fibrin in the small vessels together wit| tissue necrosis, bore a striking resemblance to $\vec{a}$ localised Shwartzman reaction. There was some experimental but never any clinical evidence tôे support this interesting theory. However, if the antigen entering the bowel wall was an endotoxim then an immunological reaction could be produce as well as a Shwartzman reaction, although the 
time scale is admittedly different. Indeed it may be that the intravascular activation of complement in case 4 was due to a Shwartzman reaction.

In conclusion we have demonstrated for the first time vascular ICD occurring in the damaged bowels of three neonates with NNEC. While this may be an epiphenomenon we believe there is both immunological and histopathological evidence to support our hypothesis that at least in some cases of NNEC, immune complexes have a role in the pathogenesis of the disease possibly by increasing the vascular damage and tissue ischaemia.

We thank Mr GD Milne for his excellent technical assistance.

\section{References}

1 Tait RA, Kealy WF. Neonatal necrotising enterocolitis. J Clin Pathol 1979;32:1090-9.

2 Pedersen PV, Halveg AB, Hansen FH, Christiansen ED. Necrotising enterocolitis of the newborn-is it gas gangrene of the bowel? Lancet 1976;ii:715-6.

${ }^{3}$ Lake AM, Walker WA. Neonatal necrotising enterocolitis; a disease of altered host defence. Clin Gastroenterol 1977;
6:463-80.

${ }^{4}$ Rieger CHL, Rothberg RM. Development of the capacity to produce specific antibody to an ingested food antigen in the premature infant. $J$ Pediatr $1975 ; 87: 515-8$.

${ }^{5}$ Walker WA, Isselbacher KJ. Uptake and transport of macromolecules by the intestine: possible role in clinical disorders. Gastroenterology 1974;67:531-50.

${ }^{6}$ Lloyd JR. The etiology of gastrointestinal perforation in the newborn. J Pediatr Surg 1979;4:77-84.

${ }^{7}$ Leake RD, Thampoulos B, Nieberg R. Hyperviscosity associated with necrotising enterocolitis. Am J Dis Child 1975;129:1192-4.

${ }^{8}$ Rogers AF, Dunn PM. Intestinal perforation, exchange transfusion, and PVC. Lancet 1969;ii:1246.

9 Mizrahi A, Barlow O, Berdon W, Blanc WA, Silverman WA. Necrotising enterocolitis in premature infants. J Pediatr 1965;66:697-706.

${ }^{10}$ Goldgraber MD, Kirsner JB. The Arthus phenomenon in the colon of rabbits. Arch Pathol 1959;67:556-71.

${ }^{11}$ Hermann RE. Perforation of the colon from necrotising colitis in the newborn: report of a survival and a new etiologic concept. Surgery $1965 ; 58: 436-41$.

Requests for reprints to: Dr Elizabeth Gray, Department of Pathology, University of Aberdeen, Foresterhill, Aberdeen AB9 2ZD, Scotland. 